\title{
PENGARUH KUALITAS PELAYANAN, HARGA, DAN CITRA MEREK TERHADAP LOYALITAS PELANGGAN DENGAN KEPUASAN PELANGGAN SEBAGAI VARIABEL PEMEDIASI
}

\author{
Erni Setyowati ${ }^{1}$ dan Wiyadi \\ 1) Magister Manajemen Universitas Muhammadiyah Surakarta \\ 2) Fakultas Ekonomi dan Bisnis Universitas Muhammadiyah Surakarta, \\ Jl. Ahmad Yani, Pabelan Surakarta 57102. \\ Email: erniezt_rushthy@yahoo.com
}

\begin{abstract}
Abstrak
Penelitian ini bertujuan untuk mengetahui dan menganalisis pengaruh: 1) kualitas pelayanan terhadap kepuasan pelanggan, 2) harga terhadap kepuasan pelanggan, 3) citra merek terhadap kepuasan pelanggan, 4) kualitas pelayanan terhadap loyalitas pelanggan, 5) harga terhadap loyalitas pelanggan, 6) citra merek terhadap loyalitas pelanggan, dan 7) kepuasan pelanggan terhadap loyalitas pelanggan. Data yang digunakan adalah data primer yang diperoleh dari jawaban 100 orang responden dengan metode accidental sampling. Alat analisis data menggunakan analisis jalur (path analysis). Hasil pengujian instrumen menyimpulkan bahwa semua variabel valid dan reliabel sebagai alat pengumpul data. Dari hasil analisis data didapatkan bahwa: 1) kualitas pelayanan berpengaruh positif dan signifikan terhadap kepuasan pelanggan, 2) harga berpengaruh positif dan signifikan terhadap kepuasan pelanggan, 3) citra merek berpengaruh positif dan signifikan terhadap kepuasan pelanggan, 4) kualitas pelayanan berpengaruh positif dan signifikan terhadap loyalitas pelanggan, 5) harga berpengaruh positif dan signifikan terhadap loyalitas pelanggan, 6) citra merek berpengaruh positif dan signifikan terhadap loyalitas pelanggan, 7) kepuasan pelanggan berpengaruh positif dan signifikan terhadap loyalitas pelanggan.
\end{abstract}

Kata Kunci: kualitas pelayanan, harga, citra merek, kepuasan pelanggan, loyalitas.

\begin{abstract}
This research aims to identify and analyze: 1) the quality of service to customers satisfaction, 2) price to customers satisfaction, 3) brand image on customers satisfaction, 4) quality of service to customers loyalty, 5) price to customers loyalty, 6) brand image to customers loyalty, 7) customers satisfaction to customers loyalty. The data of this research is the premier data which was obtained from the answers of 100 respondents with accidental sampling method. This research is using path analysis. The test result concluded that all variables instrument are valid and reliable as a data collecting tool. In the data analysis shows that: 1) service quality has positive and significant effect on customers satisfaction, 2) price has the positive and significant impact on customers satisfaction, 3) brand image has positive and significant impact on customers satisfaction, 4) the quality of service has positive and significant effect on the customers loyalty, 5) price has positive and significant effect on customers loyalty, 6) brand image has positive and significant effect on customers loyalty, 7) customers satisfaction has positive and significant effect on the customers loyalty.
\end{abstract}

Keywords: service quality, price, brand image, customers satisfaction, loyalty. 


\section{Pendahuluan}

Loyalitas pelanggan dipengaruhi oleh banyak faktor, di antaranya kualitas pelayanan, harga, dan citra merek. Namun, loyalitas pelanggan dapat terwujud jika seorang pelanggan merasa puas atas apa yang diberikan oleh perusahaan. Untuk mencapai kepuasan pelanggan, sebuah perusahaan harus mampu memberikan kualitas pelayanan yang maksimal, harga yang dapat dijangkau, dan citra merek yang baik di mata para pelanggan. Bisnis dalam bidang jasa merupakan bisnis yang dipandang tidak akan pernah mengalami kebangkrutan karena pada dasarnya manusia adalah makhluk sosial yang terus membutuhkan bantuan orang lain untuk menyelesaikan berbagai hal.

Salah satu contoh bisnis dalam bidang jasa adalah jasa pengiriman. Bisnis ini dapat membantu seseorang untuk mengirimkan benda kepada orang lain yang berjarak dekat maupun jauh. JNE adalah perusahaan jasa pengiriman barang yang telah tersebar di seluruh Indonesia. Salah satu cabang JNE berada di kota Solo beralamat di JL. Adi Sucipto No. 29 Colomadu. Ada beberapa jenis layanan paket pengiriman barang yang ditawarkan oleh JNE kepada para pelanggan di antaranya layanan OKE (ongkos kirim ekonomis), layanan REG (regular), YES (yakin esok sampai), dan SS (special service).

Saat ini telah banyak ancaman dari pendatang baru dalam bisnis yang sejenis seperti Asperindo, DHL, Pos Indonesia, Fedex, Cahaya Nusantara Express, Cito Express, dan lain-lain. Hal ini mendasari JNE untuk berjuang keras menghasilkan produk dan layanan yang menarik dan inovatif agar dapat menarik pelanggan yang baru dan dapat mempertahankan pelanggan yang lama.

Menurut Samuel dan Wijaya dalam Masruri dan Supriyatin (2013), loyalitas pelanggan dapat terwujud jika tercapainya sebuah kepuasan pada pelanggan dan salah satu cara untuk mencapai kepuasan tersebut jika perusahaan dapat memberikan kualitas pelayanan yang baik sehingga tertanam sebuah kepercayaan dari pelanggan. Jika seorang pelanggan merasa puas atas kualitas pelayanan yang diterimanya maka pelanggan tersebut akan terus melakukan pembelian ulang.

Menurut Cronin dan Taylor (dalam Sondakh, 2014), semakin tinggi tingkat kualitas pelayanan yang diberikan dan dirasakan, maka akan semakin tinggi tingkat kepuasan pelanggan yang kemudian akan menghasilkan sebuah loyalitas pelanggan. Hasil penelitian Baker dan Crompton (2000), menemukan bahwa kualitas pelayanan secara positif dan signifikan berkorelasi dengan loyalitas pelanggan.

Selain kualitas pelayanan yang diberikan oleh perusahaan kepada para pelanggan, harga juga mempunyai peluang untuk mencapai kepuasan dan menciptakan loyalitas pelanggan. Menurut Oliver dalam Malik et al. (2012), pelanggan merasa penentuan harga yang sesuai dengan kualitas akan memberikan rasa kepuasan. Penelitian yang dilakukan oleh Bei dan Chiao dalam Malik et al. (2012), menemukan bahwa keadilan harga berpengaruh positif dan signifikan terhadap kepuasan, dan berpengaruh secara langsung maupun secara tidak langsung dengan loyalitas yang diperantarai oleh kepuasan pelanggan.

Citra merek juga mempunyai peluang untuk mencapai kepuasan dan menciptakan sebuah loyalitas pelanggan. Menurut Setiadi dalam Sondakh (2014), citra terhadap suatu merek menjadi dasar pelanggan untuk melakukan pembelian. Dengan mempunyai citra merek yang baik maka para pelanggan dapat mengenali produk atau jasa yang akan dibelinya, mengetahui kualitas produk tersebut, dan memperoleh pengalaman dari produk tersebut yang kemudian bisa merekomendasikan kepada orang lain. Penelitian Ogba dan Tan (2009), mengungkapkan ada efek positif dari citra merek pada loyalitas pelangggan.

Berdasarkan latar belakang masalah tersebut maka penulis tertarik untuk melakukan penelitian mengenai pengaruh kualitas pelayanan, harga dan citra merek 
terhadap loyalitas pelanggan dengan kepuasan pelanggan sebagai variabel pemediasi di PT. JNE Cabang Solo.

\section{Tinjauan Pustaka}

\section{Kualitas Pelayanan}

Definisi kualitas menurut Kotler (1997) adalah segala sesuatu yang dimiliki oleh suatu produk barang maupun jasa yang dapat memenuhi kebutuhan dan dapat memberikan kepuasan kepada para pelanggan. Kotler (2000), mendefinisikan pelayanan adalah sebuah strategi yang dibuat oleh perusahaan karena suatu produk perusahaan tidak hanya berupa barang tetapi juga dapat berupa sebuah pelayanan. Berdasarkan pada beberapa definisi tersebut, maka kualitas pelayanan adalah berbagai usaha yang dilakukan oleh perusahaan untuk memenuhi kebutuhan dan harapan para pelanggan.

Menurut Tjiptono (2007) ada lima dimensi kualitas pelayanan, yaitu:

a. Keandalan (reliability). Suatu kemampuan perusahaan untuk memenuhi kebutuhan para pelanggan dalam hal pelayanan secara cepat, akurat, dan tepat waktu sehingga akan memuaskan para pelanggan.

b. Daya tanggap (responsiveness). Inisiatif yang muncul dari para karyawan untuk memberikan pelayanan secara cepat dan tanggap kepada para pelanggan.

c. Jaminan (assurance). Sikap atau sifat para karyawan yang dapat menanamkan benih kepercayaan di benak para pelanggan yang meliputi sikap sopan, berpengetahuan, berkompeten, dan dapat dipercaya sehingga para pelanggan akan merasa aman dan nyaman terhadap pelayanan yang diberikan oleh perusahaan tersebut.

d. Perhatian (empathy). Suatu bentuk perhatian yang diberikan oleh perusahaan kepada para pelanggan, perhatian tersebut dapat berupa pemahaman terhadap kebutuhan para pelanggan dan perhatian dalam memberikan kemudahan berkomunikasi dengan pihak perusahaan. e. Bukti fisik (tangibles). Bukti fisik dapat berupa karyawan yang berkompeten, penyediaan fasilitas yang lengkap, dan peralatan komunikasi yang modern dan canggih.

\section{Harga}

Menurut Tjiptono (2007), ada tiga peranan dari harga, yaitu:

a. Bagi perekonomian, dalam perekonomian untuk menentukan besarnya tingkat upah, laba, bunga, dan sewa berdasarkan oleh harga.

b. Bagi konsumen, harga telah digunakan konsumen sebagai dasar keputusan dalam pembelian suatu produk maupun jasa.

c. Bagi perusahaan, pendapatan sebuah perusahaan dapat diperoleh dari harga yang telah ditentukan oleh perusahaan tersebut.

Menurut Chandra dalam Tjiptono (2007)

dimensi strategis harga ada tujuh, yaitu:

a. Harga merupakan sebuah nilai yang dimiliki oleh suatu produk barang atau jasa.

b. Harga adalah sesuatu yang jelas bagi para pelanggan.

c. Harga adalah faktor utama untuk memperoleh permintaan.

d. Harga merupakan dasar untuk memperoleh pendapatan dan laba.

e. Harga memiliki sifat fleksibel.

f. Harga merupakan faktor untuk menentukan strategi perusahan dan akan berpengaruh pada citra perusahaan.

g. Harga merupakan permasalahan utama bagi manajer.

\section{Citra Merek}

Citra merek didefinisikan oleh Keller dalam Malik et al. (2012), sebagai sebuah asumsi atau pendapat tentang merek dalam pikiran pelanggan yang harus dipertahankan. Citra Merek adalah suatu kepercayaan yang muncul dari seorang konsumen terhadap suatu merek produk barang atau jasa.

Schiffman dan Kanuk (dalam Fajrianthi, 
2005) berpendapat ada beberapa faktor pembentuk citra merek, yaitu:

a. Kualitas berhubungan dengan kualitas produk barang atau jasa yang disediakan oleh perusahaan penyedia jasa tersebut.

b. Dapat dipercaya, berhubungan dengan asumsi dari para konsumen yang telah mengkonsumsi produk tersebut.

c. Kegunaan, berhubungan dengan kegunaan suatu produk barang atau jasa yang dapat dirasakan oleh para pelanggan.

d. Pelayanan, berhubungan dengan hal-hal yang harus dilakukan oleh perusahaan dalam memberikan pelayanan kepada para pelanggan.

e. Risiko, berhubungan dengan segala sesuatu yang muncul yang akan ditanggung oleh para pelanggan.

f. Harga, berkaitan dengan tinggi rendahnya uang yang akan dikeluarkan seorang konsumen untuk sebuah produk.

g. Citra dari merek itu sendiri, berhubungan dengan merek dari produk itu sendiri.

\section{Kepuasan Pelanggan}

Menurut Kotler dalam Tjiptono (2007) kepuasan pelanggan adalah suatu keadaan yang dirasakan oleh seseorang ketika apa yang dirasakan telah sesuai dengan harapannya. Menurut Tjiptono (2008) ada beberapa manfaat dari kepuasan pelanggan, yaitu:

a. Terjalinnya sebuah hubungan yang baik antara perusahaan dan pelanggan.

b. Dapat menciptakan sebuah loyalitas pelanggan.

c. Dapat menjadi media iklan yang efektif melalui word of mouth.

Menurut Nasution (2001) kepuasan pelanggan dapat diidentifikasi dan dipantau dengan beberapa metode, yaitu:

a. Metode keluhan dan saran, dilakukan melalui kotak saran dan komentar. Keluhan-keluhan dari pelanggan ini dapat dijadikan sebagai sumber inspirasi bagi perusahaan untuk memperbaiki layanan. b. Melakukan survei kepuasan pelanggan, melalui cara ini maka perusahaan dapat memperoleh respons langsung dari pelanggan.

c. Lost customer analysis, metode ini dilakukan dengan cara perusahaan melakukan penelitian pada pelanggan yang telah berhenti melakukan pembelian untuk mengetahui alasan mengapa mereka berhenti dan dapat mengetahui kelemahan produk tersebut.

d. Chost shopping, metode ini dilakukan untuk membandingkan kelemahan dan kelebihan produk perusahaan dengan pesaing.

\section{Loyalitas Pelanggan}

Definisi loyalitas menurut Lovelock dan Wright (2005) adalah kesetian seorang pelanggan untuk menggunakan produk sebuah perusahaan dalam waktu yang lama. Menurut Griffin (2005) loyalitas dapat dibagi menjadi empat jenis, yaitu:

Tanpa loyalitas. Pada loyalitas jenis ini seorang pelanggan dalam melakukan pembelian ulang sangat rendah dan perusahaan tidak akan mendapatkan pelanggan yang setia terhadap produknya.

Loyalitas yang lemah. Pada loyalitas jenis ini tingkat pembelian ulang seorang pelanggan terhadap suatu produk barang maupun jasa tinggi dengan keterikatan yang rendah. Dalam jenis loyalitas ini, faktor kebiasaan menjadi dasar pelanggan untuk melakukan pembelian suatu produk barang maupun jasa.

Loyalitas tersembunyi. Pada loyalitas jenis ini tingkat pembelian ulang seorang pelanggan terhadap suatu produk barang maupun jasa rendah dengan keterikatan yang tinggi. Dalam jenis loyalitas ini, faktor situasi menjadi dasar pelanggan untuk melakukan pembelian.

Loyalitas premium. Pada loyalitas jenis ini tingkat pembelian ulang seorang pelanggan terhadap suatu produk barang maupun jasa tinggi dengan keterikatan yang tinggi dan loyalitas jenis ini merupakan jenis loyalitas yang paling mudah untuk ditingkatkan. 


\section{Metode Penelitian}

Penelitian ini merupakan penelitian penjelasan, yaitu sebuah penelitian mengenai hubungan antara variabel-variabel penelitian dengan melakukan pengujian hipotesis yang telah dibuat sebelumnya (Ghozali, 2005), yaitu hubungan kualitas pelayanan, harga, dan citra merek terhadap loyalitas pelanggan dengan kepuasan pelanggan sebagai variabel mediasi.

Populasi dalam penelitian ini adalah semua pelanggan yang menggunakan jasa pelayanan pada PT. JNE cabang Solo. Metode penentuan sampel yang digunakan dalam penelitian ini adalah teknik non probability sampling dengan accidental sampling, yaitu teknik penentuan sampel berdasarkan kebetulan, siapa saja yang ditemui dan cocok sebagai sumber data, serta pernah menggunakan jasa pengiriman PT. JNE Cabang Solo. Jumlah sampel ditetapkan sebanyak 100 orang responden.

Data yang digunakan dalam penelitian ini adalah data primer yang berasal langsung dari jawaban para responden terhadap rangkaian pertanyaan yang diajukan oleh peneliti. Data yang diperlukan dalam penelitian ini adalah profil atau karakteristik dan tanggapan responden terhadap variabel kualitas pelayanan, harga, citra merek, kepuasan pelanggan, dan loyalitas pelanggan.

Data dikumpulkan dengan menggunakan metode kuesioner, yaitu teknik pengumpulan data yang dilakukan dengan menggunakan daftar angket yang telah disebar kepada semua responden dengan tujuan untuk mendapatkan data mengenai obyek penelitian.

Menurut Riduwan dan Kuncoro (2011), ada beberapa langkah dalam pengujian analisis jalur.

\section{Hasil Penelitian Dan Pembahasan}

1. Analisis Jalur (Path Analysis)

a. Persamaan Analisis Jalur 1
Tabel 1. Koefisien Jalur Persamaan 1

\begin{tabular}{clc}
\hline Model & & $\begin{array}{c}\text { Standardized } \\
\text { Coefficients Beta }\end{array}$ \\
\hline \multirow{1}{*}{1} & Kualitas Pelayanan & 0,183 \\
& Harga & 0,210 \\
& Citra Merek & 0,380 \\
\hline
\end{tabular}

a. Dependent Variable: Kepuasan Pelanggan

Sumber: Data Primer Diolah, 2016

Persamaan hasil analisis jalur yang terbentuk adalah:

$\mathrm{Y}_{1}=0,183\left(\mathrm{X}_{1}\right)+0,210\left(\mathrm{X}_{2}\right)+0,380\left(\mathrm{X}_{3}\right)$

b. Persamaan Analisis Jalur 2

Tabel 2. Koefisien Jalur Persamaan 2

\begin{tabular}{clc}
\hline Model & & $\begin{array}{c}\text { Standardized } \\
\text { Coefficients Beta }\end{array}$ \\
\hline \multirow{2}{*}{$\mathbf{c}$} & Kualitas Pelayanan & 0,175 \\
& Harga & 0,277 \\
& Citra Merek & 0,212 \\
& Kepuasan Pelanggan & 0,233 \\
\hline
\end{tabular}

a. Dependent Variable: Loyalitas Pelanggan Sumber: Data Primer Diolah, 2016

Persamaan hasil analisis jalur yang terbentuk adalah

$$
\begin{aligned}
\mathrm{Y}_{2}= & 0,175\left(\mathrm{X}_{1}\right)+0,277\left(\mathrm{X}_{2}\right)+0,212\left(\mathrm{X}_{3}\right) \\
& +0,233\left(\mathrm{Y}_{1}\right)
\end{aligned}
$$

\section{Pengaruh Langsung dan Tidak Langsung}

a. Persamaan 1

$\mathrm{Y}_{1}=0,183\left(\mathrm{X}_{1}\right)+0,210\left(\mathrm{X}_{2}\right)+0,380\left(\mathrm{X}_{3}\right)$

Tabel 3. Pengaruh Tidak Langsung $X_{1}, X_{2}$ dan $X_{3}$ terhadap $Y_{2}$ yang dimediasi $Y_{1}$

\begin{tabular}{lc}
\hline \multicolumn{1}{c}{ Pengaruh Tidak Langsung } & $\begin{array}{c}\text { Besar } \\
\text { Kontribusi }\end{array}$ \\
\hline $\mathrm{X}_{1}$ terhadap $\mathrm{Y}_{2}$ yang dimediasi oleh $\mathrm{Y}_{1}$ & 0,183 \\
$\mathrm{X}_{2}$ terhadap $\mathrm{Y}_{2}$ yang dimediasi oleh $\mathrm{Y}_{1}$ & 0,210 \\
$\mathrm{X}_{3}$ terhadap $\mathrm{Y}_{2}$ yang dimediasi oleh $\mathrm{Y}_{1}$ & 0,380 \\
Total pengaruh $\mathrm{X}_{1}, \mathrm{X}_{2}$ dan $\mathrm{X}_{3}$ terhadap & 0,773 \\
$\mathrm{Y}_{2}$ yang dimediasi oleh $\mathrm{Y}_{1}$ & \\
\hline
\end{tabular}

Sumber: Data Primer Diolah, 2016

Dari tabel tersebut diketahui bahwa pengaruh yang dimiliki variabel kualitas pelayanan $\left(\mathrm{X}_{1}\right)$ terhadap loyalitas pelanggan $\left(\mathrm{Y}_{2}\right)$ yang dimediasi oleh variabel kepuasan 
pelanggan $\left(\mathrm{Y}_{1}\right)$ adalah sebesar 0,183 atau $18,3 \%$, pengaruh harga $\left(\mathrm{X}_{2}\right)$ terhadap loyalitas pelanggan $\left(\mathrm{Y}_{2}\right)$ yang dimediasi oleh variabel kepuasan pelanggan $\left(\mathrm{Y}_{1}\right)$ adalah sebesar 0,210 atau $21 \%$ dan pengaruh citra merek $\left(\mathrm{X}_{3}\right)$ terhadap loyalitas pelanggan $\left(\mathrm{Y}_{2}\right)$ yang dimediasi oleh variabel kepuasan pelanggan $\left(\mathrm{Y}_{1}\right)$ adalah sebesar 0,380 atau $38 \%$. Sehingga total pengaruh yang diberikan variabel kualitas pelayanan $\left(\mathrm{X}_{1}\right)$, harga $\left(\mathrm{X}_{2}\right)$ dan citra merek $\left(\mathrm{X}_{3}\right)$ terhadap loyalitas pelanggan $\left(\mathrm{Y}_{2}\right)$ yang dimediasi oleh variabel kepuasan pelanggan $\left(\mathrm{Y}_{1}\right)$ adalah sebesar 0,773 atau $77,3 \%$.

Tabel 4. Hasil Uji Determinasi Persamaan 1

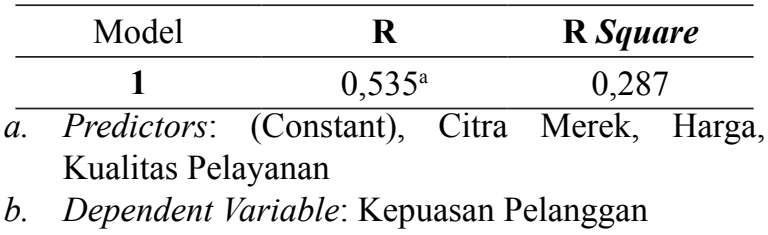

Pada tabel 4 didapat 1 model analisis jalur dengan nilai koefisien korelasi (R) sebesar 0,535 atau $53,5 \%$. Nilai R square sebesar 0,287 atau 28,7\%, ini menunjukkan bahwa variabel independen yaitu kualitas pelayanan $\left(\mathrm{X}_{1}\right)$, harga $\left(\mathrm{X}_{2}\right)$ dan citra merek $\left(\mathrm{X}_{3}\right)$ mampu menjelaskan terhadap variasi perubahan variabel kepuasan pelanggan $\left(\mathrm{Y}_{1}\right)$ sebesar $28,7 \%$. Sedangkan sisanya $(100 \%$ $28,7 \%=71,3 \%$ ) dijelaskan oleh variabel lain diluar model.

b. Persamaan 2

$$
\begin{aligned}
\mathrm{Y}_{2}= & 0,175\left(\mathrm{X}_{1}\right)+0,277\left(\mathrm{X}_{2}\right)+0,212\left(\mathrm{X}_{3}\right) \\
& +0,233\left(\mathrm{Y}_{1}\right)
\end{aligned}
$$

Tabel 5. Pengaruh Langsung $X_{1}, X_{2}, X_{3}$ dan $Y_{1}$ terhadap $Y_{2}$

\begin{tabular}{lc}
\hline \multicolumn{1}{c}{ Pengaruh Langsung } & Besar Kontribusi \\
\hline $\mathrm{X}_{1}$ terhadap $\mathrm{Y}_{2}$ & 0,175 \\
$\mathrm{X}_{2}$ terhadap $\mathrm{Y}_{2}$ & 0,277 \\
$\mathrm{X}_{3}$ terhadap $\mathrm{Y}_{2}$ & 0,212 \\
$\mathrm{Y}_{1}$ terhadap $\mathrm{Y}_{2}$ & 0,233 \\
Total Pengaruh $\mathrm{X}_{1}, \mathrm{X}_{2}, \mathrm{X}_{3}$ dan & 0,897 \\
$\mathrm{Y}_{1}$ terhadap $\mathrm{Y}_{2}$ & \\
\hline
\end{tabular}

Sumber: Data Primer Diolah, 2016
Dari tabel 5 dapat diketahui bahwa pengaruh kualitas pelayanan $\left(\mathrm{X}_{1}\right)$ terhadap loyalitas pelanggan $\left(\mathrm{Y}_{2}\right)$ adalah sebesar 0,175 atau $17,5 \%$, pengaruh harga $\left(\mathrm{X}_{2}\right)$ terhadap loyalitas pelanggan $\left(\mathrm{Y}_{2}\right)$ adalah sebesar 0,277 atau $27,7 \%$, pengaruh citra merek $\left(\mathrm{X}_{3}\right)$ terhadap loyalitas pelanggan $\left(\mathrm{Y}_{2}\right)$ adalah sebesar 0,212 atau $21,2 \%$ dan pengaruh kepuasan pelanggan $\left(\mathrm{Y}_{1}\right)$ terhadap loyalitas pelanggan $\left(\mathrm{Y}_{2}\right)$ adalah sebesar 0,233 atau $23,3 \%$. Sehingga total pengaruh yang diberikan variabel kualitas pelayanan $\left(X_{1}\right)$, harga $\left(X_{2}\right)$, citra merek $\left(\mathrm{X}_{3}\right)$ dan kepuasan pelanggan $\left(\mathrm{Y}_{1}\right)$ terhadap loyalitas pelanggan $\left(\mathrm{Y}_{2}\right)$ adalah sebesar 0,897 atau $89,7 \%$.

Tabel 6. Hasil Uji Determinasi Persamaan 2

\begin{tabular}{cccc}
\hline & Model & R & R Square \\
\hline 1 & $0,601^{\mathrm{a}}$ & 0,361 \\
\hline a. & Predictors: & (Constant), $^{\text {Pepuasan }}$ & Pelanggan, \\
& Harga, Kualitas Pelayanan, Citra Merek \\
b. & Dependent Variable: Loyalitas Pelanggan
\end{tabular}

Pada tabel 6 didapat 1 model analisis jalur dengan nilai koefisien korelasi (R) sebesar 0,601 atau $60,1 \%$. Nilai R Square sebesar 0,361 atau $36,1 \%$, ini menunjukkan bahwa variabel kualitas pelayanan $\left(\mathrm{X}_{1}\right)$ harga $\left(\mathrm{X}_{2}\right)$, citra merek $\left(\mathrm{X}_{3}\right)$ dan kepuasan pelanggan $\left(\mathrm{Y}_{1}\right)$ mampu menjelaskan terhadap variasi perubahan variabel loyalitas pelanggan $\left(\mathrm{Y}_{2}\right)$ sebesar $36,1 \%$. Sedangkan sisanya sebesar $(100 \%-36,1 \%=63,9 \%)$ dijelaskan oleh variabel lain di luar model.

\section{Pengujian Hipotesis}

a. Uji F

$$
\begin{aligned}
\text { 1) } & \text { Persamaan } 1 \\
\mathrm{Y}_{1}= & 0,183\left(\mathrm{X}_{1}\right)+0,210\left(\mathrm{X}_{2}\right) \\
& +0,380\left(\mathrm{X}_{3}\right)
\end{aligned}
$$

Tabel 7. Hasil Uji F Persamaan 1

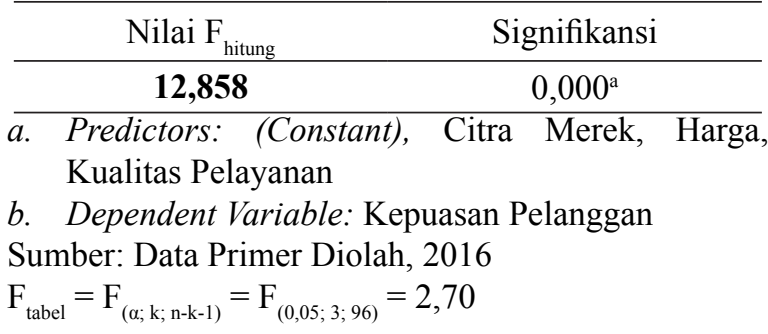


Hasil di atas menunjukkan bahwa nilai $\mathrm{F}_{\text {hitung }}$ sebesar 12,858 atau $(12,858 \geq 2,70)$ dengan signifikansi kurang dari 0,05 atau $(0,000<0,05)$, sehingga pemilihan variabel kualitas pelayanan, harga, dan citra merek telah tepat untuk dapat menjelaskan variabel kepuasan pelanggan.

2) Persamaan 2

$$
\begin{aligned}
\mathrm{Y}_{2}= & 0,175\left(\mathrm{X}_{1}\right)+0,277\left(\mathrm{X}_{2}\right) \\
& +0,212\left(\mathrm{X}_{3}\right)+0,233\left(\mathrm{Y}_{1}\right)
\end{aligned}
$$

Tabel 8. Hasil Uji F Persamaan 2

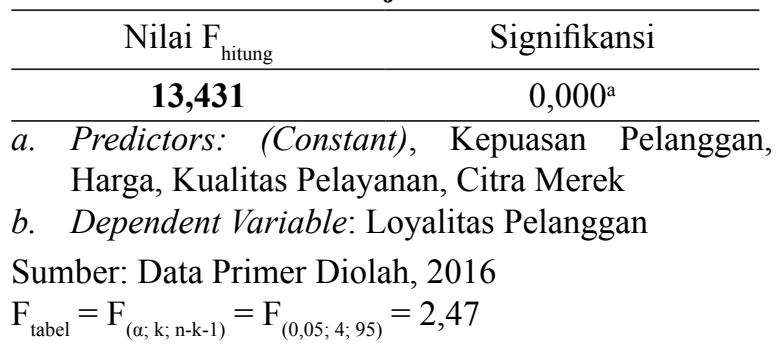

Hasil diatas menunjukkan bahwa nilai $\mathrm{F}_{\text {hitung }}$ sebesar 13,431 atau $(13,431 \geq 2,47)$ dengan signifikansi kurang dari 0,05 atau $(0,000<0,05)$, sehingga pemilihan variabel kualitas pelayanan, harga, citra merek, dan kepuasan pelanggan telah tepat untuk dapat menjelaskan variabel loyalitas pelanggan.

b. Uji t

1) Persamaan 1

$\begin{aligned} \mathrm{Y}_{1}= & 0,183\left(\mathrm{X}_{1}\right)+0,210\left(\mathrm{X}_{2}\right) \\ & +0,380\left(\mathrm{X}_{3}\right)\end{aligned}$

Tabel 9. Hasil Uji t Persamaan 1

\begin{tabular}{llcc}
\hline \multicolumn{1}{c}{ Model } & Nilai $_{\text {hitung }}$ & Signifikansi \\
\hline 1 & Kualitas Pelayanan & 2,060 & 0,042 \\
& Harga & 2,397 & 0,018 \\
Citra Merek & 4,270 & 0,000 \\
\hline
\end{tabular}

a. Dependent Variable: Kepuasan Pelanggan Sumber: Data Primer Diolah, 2016

$\mathrm{t}_{\text {tabel }}=\mathrm{t}_{(\alpha / 2 ; \mathrm{n}-\mathrm{k}-1)}=\mathrm{t}_{(0,025 ; 96)}=1,985$

\section{Pengujian Hipotesis Pertama}

Hasil pengolahan data diperoleh nilai $t_{\text {hitung }}$ sebesar 2,060 dan $\mathrm{p}$ value
0,042 sehingga nilai $t_{\text {hitung }}$ lebih besar dari $t_{\text {tabel }}$ atau $(2,060>1,985)$ dan $\mathrm{p}$ value lebih kecil dari 0,05 atau $(0,042<0,05)$, maka $\mathrm{H}_{0}$ ditolak artinya kualitas pelayanan berpengaruh positif dan signifikan terhadap kepuasan pelanggan.

\section{Pengujian Hipotesis Kedua}

Hasil pengolahan data diperoleh nilai $t_{\text {hitung }}$ sebesar 2,397 dan $\mathrm{p}$ value 0,018 sehingga nilai $t_{\text {hitung }}$ lebih besar dari $t_{\text {tabel }}$ atau $(2,397>1,985)$ dan $\mathrm{p}$ value lebih kecil dari 0,05 atau $(0,018<0,05)$, maka $\mathrm{H}_{0}$ ditolak artinya harga berpengaruh positif dan signifikan terhadap kepuasan pelanggan.

\section{Pengujian Hipotesis Ketiga}

Hasil pengolahan data diperoleh nilai $t_{\text {hitung }}$ sebesar 4,270 dan $\mathrm{p}$ value 0,000 sehingga nilai $t_{\text {hitung }}$ lebih besar dari $t_{\text {tabel }}$ atau $(4,270>1,985)$ dan $\mathrm{p}$ value lebih kecil dari 0,05 atau $(0,000<0,05)$, maka $\mathrm{H}_{0}$ ditolak artinya citra merek berpengaruh positif dan signifikan terhadap kepuasan pelanggan.

2) Persamaan 2

$$
\begin{aligned}
\mathrm{Y}_{2}= & 0,175\left(\mathrm{X}_{1}\right)+0,277\left(\mathrm{X}_{2}\right) \\
& +0,212\left(\mathrm{X}_{3}\right)+0,233\left(\mathrm{Y}_{1}\right)
\end{aligned}
$$

Tabel 10. Hasil Uji t Persamaan 2

\begin{tabular}{llcc}
\hline \multicolumn{2}{c}{ Model } & Nilai $_{\text {hitung }}$ & Signifikansi \\
\hline 1 & Kualitas Pelayanan & 2,027 & 0,046 \\
& Harga & 3,230 & 0,002 \\
Citra Merek & 2,298 & 0,024 \\
\multicolumn{2}{c}{ Kepuasan Pelanggan } & 2,404 & 0,018 \\
\hline a. Dependent Variable: Loyalitas Pelanggan \\
Sumber: Data Primer Diolah, 2016 \\
$\mathrm{t}_{\text {tabel }}=\mathrm{t}_{(\alpha / 2 ; \mathrm{n}-\mathrm{k}-1)}=\mathrm{t}_{(0,025 ; 95)}=1,985$
\end{tabular}

\section{Pengujian Hipotesis Keempat}

Hasil pengolahan data diperoleh nilai $t_{\text {hitung }}$ sebesar 2,027 dan $\mathrm{p}$ value 0,046 sehingga nilai $t_{\text {hitung }}$ lebih besar dari $\mathrm{t}_{\text {tabel }}$ atau $(2,027>1,985)$ 
dan $\mathrm{p}$ value lebih kecil dari 0,05 atau $(0,046<0,05)$, maka $\mathrm{H}_{0}$ ditolak artinya kualitas pelayanan berpengaruh positif dan signifikan terhadap loyalitas pelanggan.

\section{Pengujian Hipotesis Kelima}

Hasil pengolahan data diperoleh nilai $\mathrm{t}_{\text {hitung }}$ sebesar 3,230 dan $\mathrm{p}$ value 0,002 sehingga nilai $t_{\text {hitung }}$ lebih besar dari $t_{\text {tabel }}$ atau $(3,230>1,985)$ dan $\mathrm{p}$ value lebih kecil dari 0,05 atau $(0,002<0,05)$, maka $\mathrm{H}_{0}$ ditolak artinya harga berpengaruh positif dan signifikan terhadap loyalitas pelanggan.

\section{Pengujian Hipotesis Keenam}

Hasil pengolahan data diperoleh nilai $\mathrm{t}_{\text {hitung }}$ sebesar 2,298 dan $\mathrm{p}$ value 0,024 sehingga nilai $t_{\text {hitung }}$ lebih besar dari $t_{\text {tabel }}$ atau $(2,298>1,985)$ dan $\mathrm{p}$ value lebih kecil dari 0,05 atau $(0,024<0,05)$, maka $\mathrm{H}_{0}$ ditolak artinya citra merek berpengaruh positif dan signifikan terhadap loyalitas pelanggan.

\section{Pengujian Hipotesis Ketujuh}

Hasil pengolahan data diperoleh nilai $t_{\text {hitung }}$ sebesar 2,404 dan $\mathrm{p}$ value 0,018 sehingga nilai $t_{\text {hitung }}$ lebih besar dari $t_{\text {tabel }}$ atau $(2,404>1,985)$ dan $\mathrm{p}$ value lebih kecil dari 0,05 atau $(0,018<0,05)$, maka $\mathrm{H}_{0}$ ditolak artinya kepuasan pelanggan berpengaruh positif dan signifikan terhadap loyalitas pelanggan.

\section{Pengaruh Kualitas Pelayanan, Harga, dan Citra Merek Terhadap Kepuasan Pelanggan}

Hasil penelitian menunjukkan bahwa variabel kualitas pelayanan $\left(\mathrm{X}_{1}\right)$ berpengaruh positif dan signifikan terhadap kepuasan pelanggan $\left(\mathrm{Y}_{1}\right)$. Artinya semakin baik kualitas pelayanan sebuah perusahaan maka semakin tinggi pula kepuasan pelanggan atau semakin buruk kualitas pelayanan sebuah perusahaan maka semakin rendah kepuasan pelanggan. Sehingga hipotesis pertama dalam penelitian ini telah terbukti kebenarannya. Hasil penelitian ini sesuai dengan penelitian yang dilakukan oleh Malik et al. (2012), Sondakh et al. (2014), dan Wendha et al. (2013).

Variabel harga $\left(\mathrm{X}_{2}\right)$ memberikan pengaruh secara positif dan signifikan terhadap kepuasan pelanggan $\left(\mathrm{Y}_{1}\right)$. Hal ini berarti semakin baik persepsi pelanggan terhadap harga maka semakin tinggi kepuasan pelanggan atau semakin buruk persepsi pelanggan terhadap harga maka semakin rendah kepuasan pelanggan. Sehingga hasil penelitian ini telah sesuai dengan hipotesis kedua. Hasil penelitian ini mendukung hasil penelitian yang dilakukan oleh Malik et al. (2012) dan Bei dan Chiao (2001).

Variabel citra merek berpengaruh positif dan signifikan terhadap kepuasan pelanggan $\left(\mathrm{Y}_{1}\right)$. Ini berarti semakin baik citra merek sebuah perusahaan maka semakin tinggi kepuasan pelanggan atau semakin buruk citra merek sebuah perusahaan maka semakin rendah kepuasan pelanggan. Jadi hipotesis ketiga dalam penelitan ini telah terbukti kebenarannya. Hasil penelitian ini konsisten dengan hasil penelitian yang dilakukan oleh Malik et al. (2012) dan Diab (2009).

Karena variabel kualitas pelayanan $\left(\mathrm{X}_{1}\right)$, harga $\left(\mathrm{X}_{2}\right)$ dan citra merek $\left(\mathrm{X}_{3}\right)$ berpengaruh secara positif dan signifikan terhadap kepuasan pelanggan $\left(\mathrm{Y}_{1}\right)$, sehingga pihak perusahaan harus meningkatkan pelayanan yang lebih baik kepada pelanggan, menetapkan harga sesuai dengan pelayanan dan meningkatkan image perusahaan yang lebih baik lagi agar dapat tercipta sebuah kepuasan pelanggan.

\section{Pengaruh Kualitas Pelayanan, Harga, Citra Merek, dan Kepuasan Pelanggan Terhadap Loyalitas Pelanggan}

Variabel kualitas pelayanan memiliki pengaruh secara positif dan signifikan terhadap loyalitas pelanggan. Artinya semakin tinggi kualitas pelayanan sebuah 
perusahaan maka semakin tinggi loyalitas pelanggan atau semakin rendah kualitas pelayanan sebuah perusahaan maka semakin rendah loyalitas pelanggan. Sehingga hipotesis keempat dalam penelitian ini telah terbukti kebenarannya. Hasil penelitian ini sesuai dengan penelitian yang dilakukan oleh Joshua dan Haryadi (2013) dan Baker dan Crompton (2000).

Pada penelitian ini variabel harga berpengaruh terhadap loyalitas pelanggan. Hal ini berarti semakin baik persepsi pelanggan terhadap harga maka semakin tinggi loyalitas pelanggan atau semakin buruk persepsi pelanggan terhadap harga maka semakin rendah loyalitas pelanggan. Jadi hipotesis kelima dalam penelitian ini telah terbukti kebenarannya. Hasil penelitian ini sesuai dengan penelitian yang dilakukan oleh Malik et al. (2012) dan Kandampully dan Suhartanto (2003).

Pada variabel citra merek memiliki pengaruh yang signifikan terhadap loyalitas pelanggan. Ini berarti semakin baik citra merek perusahaan maka semakin tinggi loyalitas pelanggan atau semakin buruk citra merek perusahaan maka semakin rendah loyalitas pelanggan. Hipotesis keenam dalam penelitian ini telah terbukti kebenarannya. Hasil penelitian ini sesuai dengan penelitian yang dilakukan oleh Joshua dan Haryadi (2013) dan Ogba dan Tan (2009).

Sedangkan pada variabel kepuasan pelanggan memiliki pengaruh yang signifikan terhadap loyalitas pelanggan. Artinya semakin tinggi kepuasan pelanggan maka semakin tinggi pula loyalitas pelanggan atau semakin rendah kepuasan pelanggan maka semakin rendah pula loyalitas pelanggan. Jadi hipotesis ketujuh dalam penelitian ini telah terbukti kebenarannya. Hasil penelitian ini sesuai dengan penelitian yang dilakukan oleh Sondakh (2014) dan Sugiharto (2007).

\section{Penutup}

Berdasarkan uraian pada bab terdahulu, khususnya dalam analisis dan pembahasan selanjutnya dapat ditarik kesimpulan sebagai berikut:

1. Variabel kualitas pelayanan memberikan pengaruh secara positif dan signifikan terhadap kepuasan pelanggan. Sehingga hipotesis pertama dalam penelitian ini terbukti kebenarannya.

2. Variabel harga memberikan pengaruh secara positif dan signifikan terhadap kepuasan pelanggan. Sehingga hipotesis kedua dalam penelitian ini terbukti kebenarannya.

3. Variabel citra merek memberikan pengaruh secara positif dan signifikan terhadap kepuasan pelanggan. Sehingga hipotesis ketiga dalam penelitian ini terbukti kebenarannya.

4. Variabel kualitas pelayanan memberikan pengaruh secara positif dan signifikan terhadap loyalitas pelanggan. Sehingga hipotesis keempat dalam penelitian ini terbukti kebenarannya.

5. Variabel harga memberikan pengaruh secara positif dan signifikan terhadap loyalitas pelanggan. Sehingga hipotesis kelima dalam penelitian ini terbukti kebenarannya.

6. Variabel citra merek memberikan pengaruh secara positif dan signifikan terhadap loyalitas pelanggan. Sehingga hipotesis keenam dalam penelitian ini terbukti kebenarannya.

7. Variabel kepuasan pelanggan memberikan pengaruh secara positif dan signifikan terhadap loyalitas pelanggan. Sehingga hipotesis ketujuh dalam penelitian ini terbukti kebenarannya.

Berdasarkan hasil penelitian maka perlu disampaikan saran Bagi PT. JNE Cabang Solo untuk meningkatkan ketepatan waktu dalam penyampaian pelayanan, lebih teliti dalam penyimpanan catatan dan dokumen, meningkatkan dan menjaga kualitas karyawan yang berkompeten, menetapkan harga yang tepat (berdasarkan manfaat yang diterima pelanggan, lebih kompetitif dibanding harga pesaing dan menetapkan harga sesuai dengan kualitas pelayanan yang diberikan), dan 
berusaha keras untuk membangun kesan yang lebih baik di benak pelanggan. Bagi peneliti yang akan datang hendaknya menambah variabel bebas lainnya. Misal: nilai pelanggan, kepercayaan, word of mouth (WOM) dan sebagainya.

\section{Daftar Pustaka}

Baker, Dwayne A dan Crompton, John L. 2000. Quality, Satisfaction and Behavior Intentions. Annals of Tourism Research, Vol. 27.

Consuegra, David Martin, Molina, Arturo dan Esteban, Agueda. 2007. An Integrated Model of Price, Satisfacion and Loyalty: an Empirical Analysis in Service Sector. Jurnal of Product \& Brand Management.

Diab, Balqis. 2009. Analisis Pengaruh Nilai Pelanggan dan Citra Merek Terhadap Kepuasan Pelanggan Dalam Meningkatkan Retensi Pelanggan. Semarang: Tesis Universitas Diponegoro.

Fajrianthi, Zatul Farrah. 2005. Strategi Perluasan Merek dan Loyalitas Konsumen. Jurnal Insan Vol 7.

Ghozali, Imam. 2005. Aplikasi: Analisis Multivariate dengan Program SPSS. Semarang: Badan Penerbit Universitas Diponegoro.

Griffin, Jill. 2005. Customer Loyalty: Menumbuhkan dan Mempertahankan Kesetiaan Pelanggan. Jakarta: Erlangga.

Joshua, Timothy dan Haryadi, Eddy. 2013. Analisis Pengaruh Brand Image, Price Perception, dan Service Quality Terhadap Customer Loyalty Pada Pelanggan Urban Kitchen. Jurnal Manajemen, Vol 1 No. 1. Universitas Katolik Indonesia Atma Jaya Jakarta.

Kandampully, Jay dan Suhartanto, Dwi. 2003. The Role of Satisfaction and Image in Gaining Customer Loyalty in the Hotel Industry. Journal of Hospitality Marketing \& Management, Vol. 10.

Kotler, Philip. 1997. Manajemen Pemasaran. Jakarta: PT. Prenhallindo.

. 2000. Manajemen Pemasaran. Jakarta: Bumi Aksara.

Kotler, Philip dan Amstrong. 2005. Dasar-dasar Pemasaran. Jakarta: Pernhallindo.

Kuncoro, Mudrajat. 2013. Metode Riset Untuk Bisnis \& Ekonomi. Jakarta: Erlangga.

Lovelock, Christopher H dan Wright, Lauren K. 2005. Manajemen Pemasaran Jasa. Jakarta: PT. Indeks Kelompok Gramedia.

Malik, Fozia, Yaqoob, Sara, dan Aslam, Abid Samih. 2012. The Impact of Price Perception, Service Quality, and Brand Image on Customer Loyalty (Study of Hospitality Industry in Pakistan). Interdisciplinary Journal of Contemporary Research in Business, Vol 4 No. 5.

Malik, Muhammad Ehsan, Ghafoor, Muhammad Mudasar, dan Igbal, Hafiz Kashif. 2012. Impact of Brand Image, Service Quality and Price on Customer Satisfaction in Pakistan Telecommunication Sector. International Journal of Business and Social Science, Vol 3 No. 23.

Masruri, Annafi, dan Supriyatin. 2013. Kualitas Layanan Terhadap Kepuasan Pelanggan PT. 
Tiki Jalur Nugraha Ekakurir (JNE) Surabaya. Jurnal Ilmu \& Riset Manajemen, Vol 2 No. 7. Sekolah Tinggi Ilmu Ekonomi Indonesia (STIESIA) Surabaya.

Ogba, Ike Elechi dan Tan, Zhenzhen. 2009. Exploring the Impact of Brand Image on Customer Loyalty and Commitment in China. Journal of Technology Management in China.

Rangkuti, Freddy. 2009. Strategi Promosi Yang Kreatif. Jakarta: PT. Gramedia Pustaka Utama.

Riduwan dan Kuncoro, Engkos Achmad. 2011. Cara Menggunakan dan Memaknai Analisis Jalur (Path Analysis). Bandung: Alfabeta.

Sondakh, Conny. 2014. Kualitas Layanan, Citra Merek dan Pengaruhnya Terhadap Kepuasan Nasabah dan Loyalitas Nasabah Tabungan (Studi pada Nasabah Taplus BNI Cabang Manado). Jurnal Riset Bisnis dan Manajemen, Vol 3 No. 1. Fakultas Ekonomi dan Bisnis Universitas Sam Ratulangi.

Sugiharto, Yohanes. 2007. Pengaruh Kepuasan Terhadap Loyalitas. Vol XVIII.

Tjiptono, Fandy. 2007. Pemasaran Jasa. Malang: Bayumedia Publishing.

Wendha, Paramitha, Rahayu, Ketut, dan Suasana. 2013. Pengaruh Kualitas Layanan Terhadap Kepuasan dan Loyalitas Pelanggan Garuda Indonesia Di Denpasar. Jurnal Manajemen, Strategi Bisnis dan Kewirausahaan, Vol 7 No. 1.

Widiyanto, Joko. 2010. SPSS for Windows. Surakarta: BP FKIP UMS.

Zeithamls, A. Parasuraman dan Leonard I Berry. 2003. Delivery Quality Service: Balancing Customer Perseptions and Expectations. New York: Free Press. 